\title{
TEST BED FOR SIMULATION OF MAGNETIC FIELD MEASUREMENTS OF LOW EARTH ORBIT SATELLITES
}

\begin{abstract}
This paper presents a test bed designed to simulate the magnetic environment experienced by a spacecraft in a low Earth orbit. It consists of a spherical air bearing located inside a Helmholtz cage. The spherical air bearing is used for simulating the microgravity conditions of orbiting bodies, while the Helmholtz cage generates a controllable magnetic field resembling the one surrounding a satellite during its motion. Dedicated computer software is used to initially calculate the magnetic field in an established orbit. The magnetic field data is then translated into current values and transmitted to programmable power supplies that energize the cage. The magnetic field within the cage is finally measured by a test article mounted on the air bearing. The paper provides a description of the test bed and test article design. Experimental tests prove the good performance of the entire system.
\end{abstract}

Keywords: Helmholtz cage, air bearing, attitude determination, attitude control, nano-satellite

\section{STANOWISKO DO SYMULACJI POMIARU POLA MAGNETYCZNEGO DOKONANEGO PRZEZ SATELITE NA NISKIEJ ORBICIE ZIEMI}

\begin{abstract}
Artykut prezentuje stanowisko laboratoryjne stużące do symulowania środowiska magnetycznego, w którym porusza się satelita na niskiej orbicie ziemi. Składa się ono ze sferycznego tożyska powietrznego umieszczonego wewnątrz klatki Helmholtza. Łożysko to jest wykorzystywane do symulacji warunków mikrograwitacji doświadczanych przez orbitujace ciała, a klatka Helmholtza do generowania zadanego pola magnetycznego, podobnego do tego, jakie tam występuje. Do symulowania wartości pola magnetycznego na konkretnej orbicie wykorzystywane jest specjalistyczne oprogramowanie. Obliczone za jego pomoca wartości sa przeksztatcone na wielkości prądów, które następnie za pośrednictwem stopni mocy przekazywane sa na odpowiednie cewki składajace się na klatkę. Nastęnie pole magnetyczne powstałe $w$ klatce mierzone jest przez testowane urzadzenie osadzone na łożysku powietrznym. Artykut opisuje stanowisko oraz testowane urządzenie. Przedstawia także wyniki eksperymentu potwierdzającego dokładność całego systemu.
\end{abstract}

Stowa kluczowe: klatka Helmholtza, łożysko powietrzne, odtwarzanie orientacji, kontrola orientacji, nanosatelita

\section{INTRODUCTION}

An Attitude Determination and Control System (ADCS) is a very important part of spacecraft design. In most satellite missions, the satellite must be properly oriented. For instance, ADCS plays a major role in such satellite operations as communication, power generation with solar panels, or performing orbital maneuvers. Several solutions exist for measuring and controlling the spacecraft's attitude. In satellites of very small sizes in a Low Earth Orbit (LEO), the Earth's magnetic field measurement is often used for attitude determination and control. Small and inexpensive magnetic sensors are commonly mounted on student pico- and nano-satellites. Also, permanent magnets or electromagnetic coils (magnetorquers) are employed for attitude stabilization or control purposes. During its design phase, the ADCS is to be tested with dedicated facilities that are able to generate a controllable magnetic field and simulate the attitude dynamics of a spacecraft (Poppenk et al. 2007). The department of Robotics and Mechatronics at AGH University of Science and Technology is conducting research on the ADCS of small satellites that make use of the Earth's magnetic field. For this purpose, an in-house development ADCS test bed has been built in the AGH Space Tech Lab. The facility is composed of a Helmholtz cage surrounding a floating platform mounted on a spherical air bearing, which enables frictionless rotations of a test article within a controllable magnetic field. The cage is able to generate a magnetic field in any directions with intensity up to three times the Earth's field in our location, while the air bearing possesses a range of rotations along three axes sufficient for examining numerous aspects of the attitude dynamics of a small satellite in space. This paper describes the features of the test bed and provides an experimental validation of the full system.

The paper is structured as follows. In Section 2, the design features of the Helmholtz cage and its control unit

\footnotetext{
* AGH University of Science and Technology, Faculty of Mechanical Engineering and Robotics, Krakow, Poland; e-mail: alberto. gallina@agh.edu.pl

** AGH University of Science and Technology, Faculty of Electrical Engineering, Automatics, Computer Science and Biomedical Engineering, Krakow, Poland
} 
are presented. Section 3 describes the main properties of the air bearing used in the test bed. Section 4 is devoted to the presentation of the test article mounted on the bearing. Section 5 contains and comments on the experimental results.

\section{HELMHOLTZ CAGE}

A Helmholtz cage is an ensemble of three nearly identical pairs of coils mounted along orthogonal directions. The coils can generate a uniform magnetic field within a region inside the cage along any direction. The coils may have square or rounded shapes. For both types of shapes, an optimal value exists for the spacing between the two coils of a pair for which the level of uniformity of the generated magnetic field inside the cage is maximized. In particular, it has been proven that the optimal coil length spacing is 0.5445 for a cage with square coils (Rudd et al. 1968). Moreover, as illustrated in (Frix et al. 1994), a cage with square coils has some advantages in terms of field uniformity and construction simplicity. For this reason, this solution has been chosen in the design of the cage built in the AGH Space Tech Lab. Geometric properties of the cage are sizes of $1.5 \mathrm{~m} \times 1.5 \mathrm{~m}$ for the outer pair ( $X$ direction), $1.42 \mathrm{~m} \times 1.42 \mathrm{~m}$ for the middle pair $(Y$ direction), and $1.34 \mathrm{~m} \times 1.34 \mathrm{~m}$ for the inner pair $(Z$ direction). Each coil consists of 47 wire turns around a wooden frame. The coils of each pair have a serial connection and are powered by a programmable power unit producing currents up to $2 \mathrm{~A}$. This results in a magnetic field with maximum intensity at the center of the cage of $102 \mu \mathrm{T}$, $107 \mu \mathrm{T}$, and $114 \mu \mathrm{T}$ for the $X, Y$, and $Z$ coils, respectively. The uniformity of the magnetic field has been calculated within a $0.2 \mathrm{~m} \times 0.2 \mathrm{~m} \times 0.2 \mathrm{~m}$ workspace located at the center of the cage. The maximum magnetic field variations measured at the vertices of the workspace are below $0.7 \%$ of the magnitude measured at the cage's geometric center. A validated numerical model of the cage has also been developed that allows for estimating the magnetic field with high accuracy at any point within the cage.

The cage is energized by three 1-channel programmable power supplies. The power supplies are connected to a controller box equipped with an STM32 board that reads files with the current data from a PC, updates the output current of the power supplies, and controls the three H-bridges that adjust the polarization of the current flowing into the coils. The magnetic field to generate is initially determined by a dedicated computer program that simulates the motion of the satellite and calculates the Earth's magnetic field at the satellite position through the IGRF model (Zmuda 1971). The target magnetic vector is then converted to current values using the transformation parameters calculated in the calibration phase. The calibration phase is performed once, after the cage assembling and installation of the pedestal with the bearing. This involves sending a characteristic current signal to the coils and measuring the resultant magnetic field at the cage center by a precise magnetometer with certified calibration (Milligauss Meter MR3 from AlphaLab Inc.). Then, the following relationship is imposed:

$$
\mathbf{b}_{\mathrm{MR} 3}=\mathbf{K} \mathbf{j}_{\mathrm{c}}+\mathbf{b}_{0}
$$

where $\mathbf{b}_{\mathrm{MR} 3}$ is the magnetic field vector measured by $\mathrm{MR} 3, \mathbf{j}_{\mathrm{c}}$ is the vector of current values flowing in the $X, Y$, and $Z$ coil pairs, and $\mathbf{b}_{0}$ is the background magnetic field vector also calculated in the sensor frame when imposing $\mathbf{j}_{\mathrm{c}}=0$. Matrix $\mathbf{K}$ contains the transformation parameters to evaluate. Writing Equation (1) for a collection of $\mathbf{b}_{\mathrm{MR} 3}$ values obtained from the calibration signals permits us to calculate the terms of $\mathbf{K}$ via the least square method. The resultant $\mathbf{K}$ matrix is then used for evaluating current vector $\mathbf{j}$ producing magnetic field $\mathbf{b}_{\mathrm{s}}$ through the following relationship:

$$
\mathbf{j}=\mathbf{K}^{-1}\left(\mathbf{b}_{\mathrm{s}}-\mathbf{b}_{0}\right)
$$

The calibration signal is a stair signal where the current is varied from $-1 \mathrm{~A}$ to $1 \mathrm{~A}$ with a $0.5 \mathrm{~A}$ step. The calibrated cage is capable of generating a controllable magnetic field with good accuracy. Figure 1 shows the MR3 measurements of the calibrated cage when the target field $\left(\mathbf{b}_{\mathrm{s}}\right)$ has components varying from $-50 \mu \mathrm{T}$ to $50 \mu \mathrm{T}$ with a $25 \mu \mathrm{T}$ step.

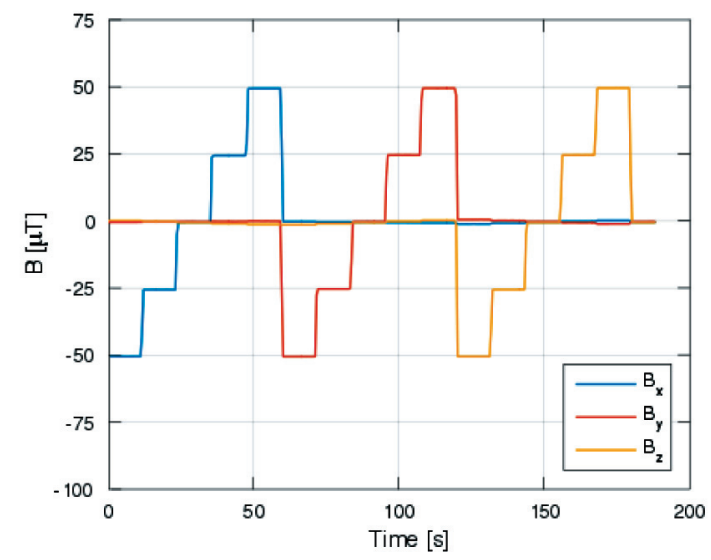

Fig. 1. Magnetic field generated by calibrated coils and measured by MR3

It should be noted that Equation (1) implies a linear relationship between the magnetic field and current according to Biot-Savart's law. Nonetheless, the calibration procedure accounts for the current supply nonlinearities, external magnetic fields, and geometric imprecision in the 
cage assembly. Figure 2 depicts a diagram with the main steps required in the calibration phase.

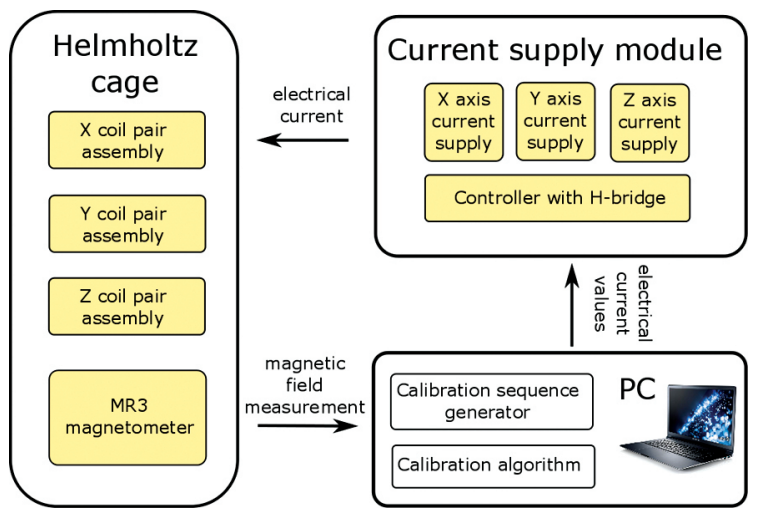

Fig. 2. Diagram of coil calibration phase

\section{AIR BEARING}

Simulating free rotations of an object in space down here on the Earth is very challenging. Different methods have been proposed for this purpose. The simplest solution consists of hanging the body upon a thin wire that enables almost frictionless rotations around the gravity direction. The solution has great advantages in terms of its readiness and costs, but it does not permit free rotations about axes orthogonal to the gravity vector. Completely free rotations can be simulated through a parabolic flight or a free-fall test. However, these tests are very expensive and can last for a very limited time; therefore, they are used for satellite dynamic analyses in very particular cases. A good trade-off between performance and cost is offered by spherical air bearings. A spherical air bearing consists of a hemispherical inner that can float on a cup (which is called a spherical outer). Air is constantly pumped between these two elements, creating a thin air layer. The spherical shape allows the bearing to rotate along three axes with no friction; however, only one axis of rotation has complete freedom, while the other two axes have limited mobility range. An issue for this kind of facility is the balancing phase where one attempts to make the center of mass of the rotating body coincident with the center of rotation of the bearing for cancelling the moment due to the gravity. Thus, whenever possible, the system is operated pendulum stable; that is, with the center of mass below the center of the instantaneous rotation of the bearing. However, this configuration obviously ensures free rotations only along a vertical axis, therefore resembling the solution with a wire.

The AGH Space Tech Lab is equipped with a small spherical air bearing with a $31.75 \mathrm{~mm}$ radius. The bearing is produced by Nelson Air Corp. The manufacturer guarantees a maximum load capacity of $16 \mathrm{~kg}$ at 4 bar. The maximum tilt angle is $45 \mathrm{deg}$. The bearing is made of hard anodized aluminum, which is a non-ferrous material that does not disturb the magnetic field generated by the Helmholtz cage. While working, the bearing is subjected to a turbine torque due to the air flow supporting the spherical inner. The intensity of this torque depends on the pressure of the flow. It has been calculated that, for small payloads with a bearing operating at 2 bar, the turbine torque is as low as a few $10^{-6} \mathrm{Nm}$. This value is only one order of magnitude greater than the expected maximum disturbance torques for nano-satellites in LEO. The bearing is mounted on an aluminum pedestal fix-supported to a heavy granite block, which makes the system firm. The air bearing has requirements for the quality of the supplied air. Dust particles in the air flow greater than $10 \mu \mathrm{m}$ could compromise the air layer at the spherical interface or obstruct the nozzles. Thus, an oil-free compressor with membrane dryer is employed for operation of the bearing. Figure 3 shows the bearing mounted on the pedestal within the cage and gives a zoom-in view of the spherical inner and outer of the bearing along with the test article described in the next section.
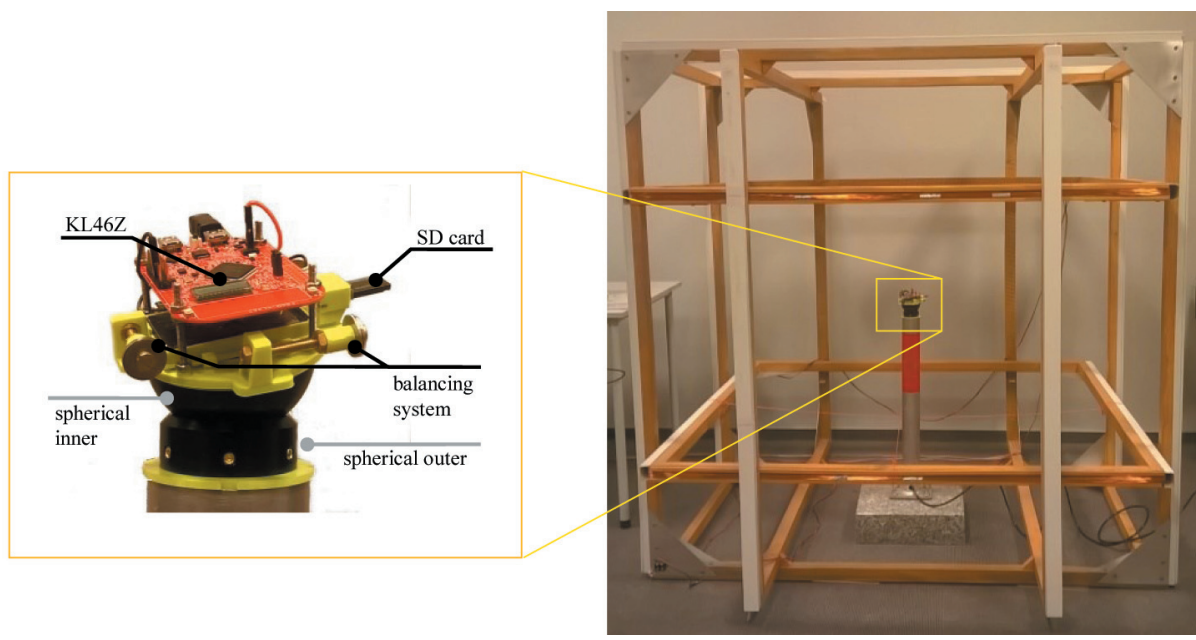

Fig. 3. Spherical inner and outer of spherical air bearing located within Helmholtz cage 


\section{TEST ARTICLE}

The test article presented in this work is a rotating system that records a variable magnetic field. It is composed of a magnetometer operated by a microcontroller that (powered by a small battery) transfers data to the storage device. The controller board is an NXP Semiconductor FRDM-KL46Z incorporating a MAG3110 3-axis magnetometer. Measurements are stored on a SD card connected to the board via USB. The measurement unit is a very light system mounted at the top of the spherical inner. Since the center of mass of the spherical inner alone is located below the center of rotation of the bearing, the presence of the measurement unit moves the center of mass of the whole system only a few millimeters upward, yet still leaves the center of mass of the whole system below the center of rotation of the bearing. Thus, the article holds a pendulum stable configuration, which is sufficient for the purposes of the conducted experiments. The test article includes a simple balancing system (see Fig. 3) for zeroing the tilt angle when the article is at its rest configuration.

Freescale's MAG3110 magnetometer is a low-power, digital 3-axis magnetometer that needs calibration. Calibration corrects for the possible misalignment of the three axes of the sensor and evaluates the sensor gains and offsets due to magnetic field disturbances caused by the nonferromagnetic components (soft ironing) and magnetic sources (hard ironing) coming from the environment and the test article's hardware. Similar to the calibration of the cage, the calibration of the test article involves the solution of a set of equations of the following kind:

$$
\mathbf{x}=(\mathbf{K T}) \mathbf{v}+\mathbf{o}
$$

where $\mathbf{v}$ is the vector of the real magnetic field components calculated with respect to a reference frame and $\mathbf{x}$ is the rough sensor measurement vector calculated with respect to the sensor frame. Matrices $\mathbf{T}$ and $\mathbf{K}$ are the upper triangular matrix correcting for any misalignment of the sensor frame with respect to the reference frame and diagonal matrix of sensor gains, respectively. Vector $\mathbf{o}$ is an offset vector. The calibration involves the calculation of the terms of $\mathbf{K}, \mathbf{T}$ and $\mathbf{o}$ from the known vectors $\mathbf{x}$ and $\mathbf{v}$ by solving Equations (3), written for different sensor orientations. The vectors $\mathbf{x}$ and $\mathbf{v}$ can be determined by rotating the test article within a uniform magnetic field. In this way the magnitude of $\mathbf{v}$ remains the same in all measurements and Equation (3) becomes the equation of an ellipsoid:

$$
\begin{aligned}
& \mathbf{v}^{\mathrm{T}} \mathbf{v}=|\mathbf{v}|^{2}=(\mathbf{x}-\mathbf{o})^{\mathrm{T}} \mathbf{A}^{\mathrm{T}} \mathbf{A}(\mathbf{x}-\mathbf{o}) \\
& \mathbf{A}=(\mathbf{K T})^{-1}
\end{aligned}
$$

Then Equation (4) can be solved for $\mathbf{K}$, T, and $\mathbf{o}$ adopting one of the methods proposed in the literature (Bonnet et al. 2009). A more general approach for calibration makes use of a variable reference magnetic field. This method leads to more robust calibrations because of taking the sensor's behavior into account at different intensities of the magnetic field. The presence of the Helmholtz cage permits us to employ the second procedure. The variable reference magnetic field is produced by activating the coils (one at a time) with a current varying from $-1 \mathrm{~A}$ to $1 \mathrm{~A}$ with a $0.2 \mathrm{~A}$ step; this is initially measured by the MR3. The terms of $\mathbf{K}, \mathbf{T}$, and $\mathbf{o}$ are then obtained by an optimization procedure. Figure 4 shows the effect of the calibration by comparing the magnitude of the calibrated and non-calibrated signals with the reference MR3 signal. The analysis of the diagrams evidences a scatter of the calibrated signal within $1.5 \mu \mathrm{T}$ and a deviation from the reference signal always within $1 \mu \mathrm{T}$. This is a good achievement when considering that the sensor noise measured by static tests (without moving the measurement unit) shows signal oscillations of $\pm 0.5 \mu \mathrm{T}$.

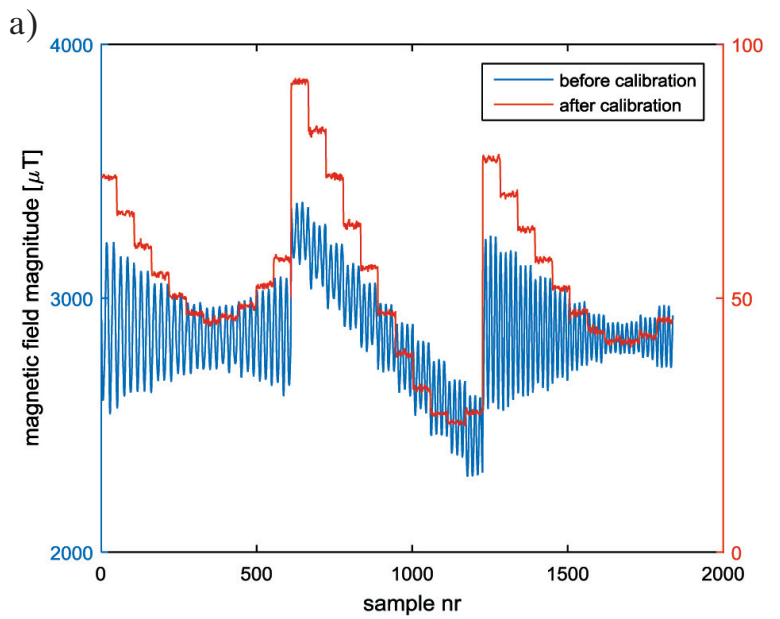

b)

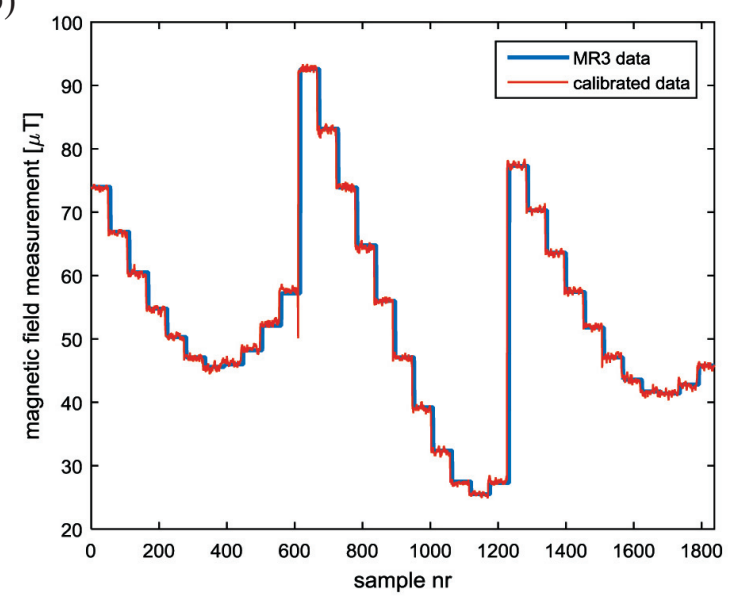

Fig. 4. Comparisons of the onboard magnetic field measurements with the reference values: a) plot of sensor measurements before and after calibration; b) plot of MR3 data vs sensor calibrated data 


\section{EXPERIMENTS}

The presented experiment consists of reproducing the Earth's magnetic field measured onboard by a spinning satellite in LEO. The orbital parameters are a semi-major axis of $7621 \mathrm{~km}$, eccentricity of 0.1 , and $45 \mathrm{deg}$. inclination. The satellite position at different time instants is calculated through an orbital propagator, and the magnetic field is determined from the IGRF model. In order to check the accuracy of the onboard measurements, the magnetic field generated by the coils is initially measured by the MR3. Then, the milligauss meter is replaced with the test article. During operations, the test article simulates the satellite's spin by slowly rotating on the bearing. Magnetic field measurements are stored onboard on an SD card and eventually transferred to a PC for data post-processing. The main steps of the experimental procedure are graphically presented in the diagram of Figure 5.

The comparison of the magnitude of the original IGRF signal with the signals measured by the MR3 and MAG3110 sensor is presented in Figure 6, for a short time interval. The agreement of the three signals is very good and in line with the results obtained in the calibration phase.

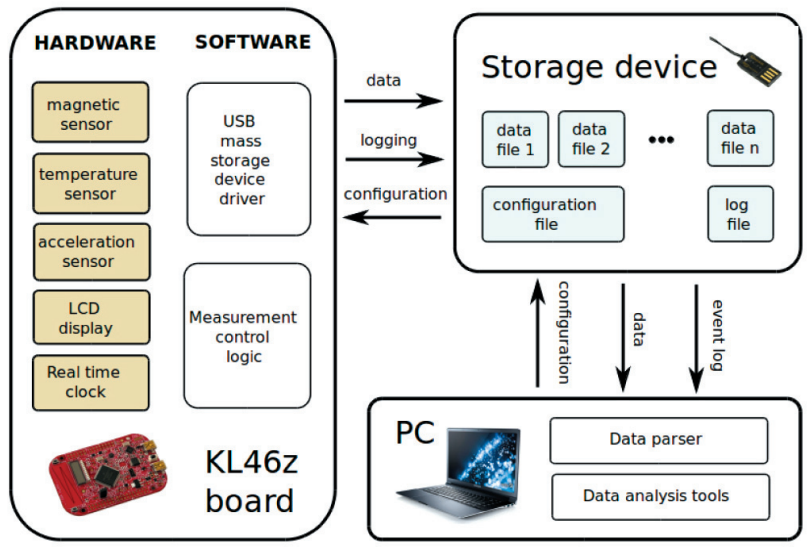

Fig. 5. Diagram of steps of simulation experiment

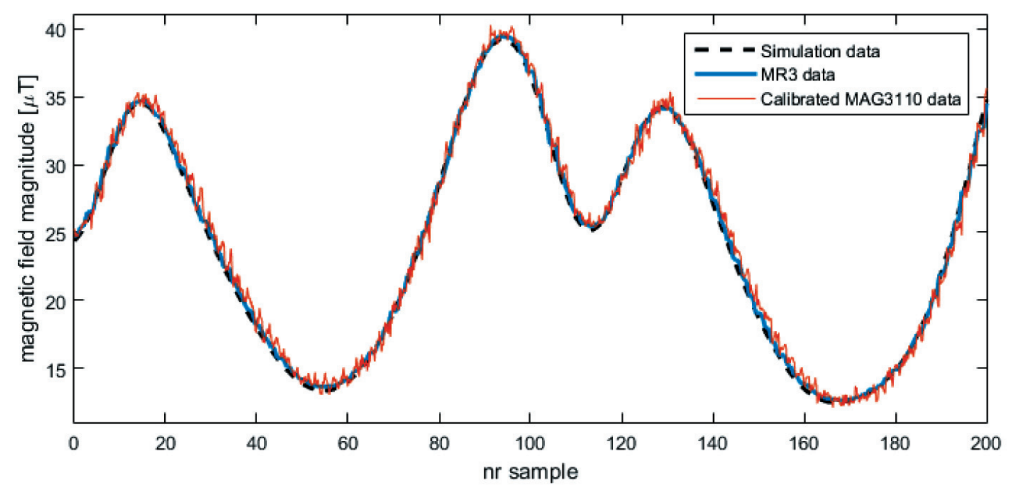

Fig. 6. Comparison of onboard measurement with numerically simulated signal

\section{CONCLUSIONS}

The paper describes the ADCS test bed built in the AGH Space Tech Lab for the simulation of onboard magnetic field measurements of an LEO satellite. The Earth's magnetic field is first numerically evaluated using Earth magnetic models and then reproduced in the lab by means of a Helmholtz cage. A measurement unit is mounted on a spherical air bearing located inside the cage. The unit records the magnetic field generated by the cage while floating on the bearing. Experiments evidence the good performance of the test bed. The facility is currently being used for both didactic and research purposes.

\section{References}

Bonnet S., Bassompierre C., Godin C., Lesecq S., Barraud A., 2009, Calibration methods for inertial and magnetic sensors. Sensors and Actuators A: Physical 156, 2, 302-311.

Frix W.M., Karady G.G., Venetz G.G., 1994, Comparison of calibration systems for magnetic field measurement equipment. IEEE Transactions on Power Delivery 9, 100-108.

Poppenk F.M., Amini R., Brouwer G.F., 2007, Design and application of Helmholtz cage for testing nano-satellites. ESA-ESTEC 6th International Symposium on Environmental Testing for Space Programmes, 12-14 June, Noordwijk, The Netherlands, editor K. Fletcher.

Rudd M.E., Craig J.R., 1968, Optimum Spacing of Square and Circular Coil Pairs. Review of Scientific Instruments 39, 9, 1372-1374.

Zmuda A.J., 1971, The world magnetic survey 1957-1969. Eos, Transactions, American Geophysical Union 52, 2, 60-67. 